\title{
Tratamento da Doença de Paget Óssea: Importância do Ácido Zoledrônico
}

RESUMO

A doença de Paget é uma doença esquelética, de distribuição monostótica ou poliostótica, podendo ser causada por uma infecção viral e/ou fatores genéticos. É caracterizada por um aumento da remodelação óssea, resultando em anormalidade da arquitetura óssea. A excessiva reabsorção óssea osteoclástica, seguida secundariamente de aumento da atividade osteoblástica, leva à substituição do osso normal por osso desorganizado, aumentado, e com estrutura enfraquecida, propensa a deformidades e fraturas. A doença de Paget pode ser diagnosticada através de exames radiológicos, cintilografia e exames bioquímicos. O objetivo primário do tratamento é reduzir a dor e o risco do aparecimento das complicações a longo prazo. Atualmente dispõe-se de drogas anti-reabsortivas potentes, as quais controlam a reabsorção óssea e proporcionam uma grande melhora no tratamento. $\mathrm{O}$ ácido zoledrônico, um bisfosfonato de última geração, tem a vantagem de maior potência e remissão mais prolongada, além de um tempo de infusão curto. (Arq Bras Endocrinol Metab 2006;50/5:845-851)

Descritores: Doença de Paget óssea; Bisfosfonatos; Calcitonina; Reabsorção óssea

\section{ABSTRACT}

Treatment of Paget's Disease of Bone: Importance of the Zoledronic Acid. Paget's disease is a localised monostotic or polyostotic bone disease of unknown origin. It may be caused by a slow viral infection and/or genetic factors. It is characterised by increased bone remodelling and an initially excessive osteoclastic bone resorption, followed by a secondary increase in osteoblastic activity, leading to replacement of the normal bone by a disorganized, enlarged, and weakened osseous structure prone to deformities and fractures. The disease may be diagnosed by radiography, scintigraphy and biochemical tests. The primary aim of treatment is to reduce pain and risk of developing long-term complications. Potent antiresorptive drugs are now available, which control the increased bone remodelling and have led to a dramatic improvement in treatment. Zoledronic acid, a new generation of bisphosphonates, has the advantage of great potency and long duration of remission and a short infusion time. (Arq Bras Endocrinol Metab 2006;50/5:845-851)

Keywords: Paget's disease of bone; Bisphosphonate; Calcitonin; Bone resorption

A DOENÇA DE PAget FOI DESCRITA pela primeira vez em 1877 pelo médico inglês Sir James Paget (1). É uma doença óssea localizada, monostótica ou poliostótica, caracterizada por um aumento da remodelação óssea, resultando em anormalidade da arquitetura óssea. A excessiva reabsorção óssea osteoclástica, seguida secundariamente de aumento da atividade osteoblástica, leva à substituição do osso normal por

\section{Luiz Griz Viviane Colares Francisco Bandeiva}

Unidade de Endocrinologia do Hospital Agamenon Magalhães, SUS/UPE; e Centro de Osteoporose, Recife, PE.
Recebido em 21/11/05

Revisado em 26/04/06 Aceito em 19/05/06 
osso desorganizado, aumentado, e com estrutura enfraquecida, propensa a deformidades e fraturas. Os principais sítios comprometidos são vértebras, ossos longos dos membros inferiores, pelve e crânio (2).

Em países onde a doença é prevalente, afeta até $3 \%$ da população com idade maior que 40 anos. Tem distribuição geográfica variável. É mais comum na Inglaterra, nos Estados Unidos, na Austrália e na Nova Zelândia, e mais rara na Escandinávia e na Ásia. No Brasil, acomete predominantemente pacientes de ascendência européia (2).

Embora de etiologia incerta, existem evidências de que uma infecção viral e/ou fatores genéticos desempenham um papel patológico. História familiar está presente em $15 \%$ dos pacientes. Parentes de primeiro grau de pacientes com doença de Paget têm 7 vezes mais risco de desenvolver a doença (3).

Evidências de associação da susceptibilidade genética com o cromossomo 6 (lócus do HLA) e 18q têm sido demonstradas com freqüência elevada, principalmente em pacientes portadores de antígenos HLA DQwl. O SQSTMl, também chamado de p-62 ou sequestosomo 1 , localizado no cromossomo $5 \mathrm{q} 35$, é uma proteína sinalizadora que parece estar envolvida nos mecanismos patogênicos por aumentar a atividade osteoclástica. Mutações (P392L) desse gene têm sido detectadas em mais de 30\% dos casos de Doença de Paget Familiar (4). Além de uma susceptibilidade genética, uma infecção viral latente parece desempenhar um papel na etiopatogenia da doença de Paget. Têm sido demonstradas inclusões nucleares e citoplasmáticas características de nucleocapsídeos virais em osteoclastos de pacientes com doença de Paget $(5,6)$, assim como uma provável relação com o vírus da família Paramixoviridae, sincicial respiratório, sarampo e $\mathrm{o}$ vírus da raiva. A seqüência completa do gene do nucleocapsídio do vírus do sarampo foi detectada em osteoclastos da medula óssea de pacientes com doença de Paget (6).

As principais manifestações clínicas incluem dor óssea, fraturas, deformidades esqueléticas e artrite secundária (7). Na maioria dos casos, o diagnóstico da doença de Paget pode ser feito através da combinação dos sintomas, achados radiológicos e elevação da concentração dos marcadores bioquímicos da remodelação óssea (8). O principal método diagnóstico é o radiológico. Observam-se lesões mistas, com áreas de osteólise (lesões em forma de chama de vela em ossos longos e osteoporose circunscrita no crânio), resultantes do aumento da atividade osteoclástica e lesões escleróticas, resultantes do aumento da formação óssea, ossos aumentados de tamanho, espessamento cortical e alterações escleróticas (8,9). A cintilografia óssea, apesar de pouco específica, tem alta sensibilidade. As áreas suspeitas devem ser avaliadas em seguida com raio-X simples, para proporcionar informações a respeito de fraturas e lesões líticas (10). Os níveis de cálcio e fósforo séricos são normais. Hipercalcemia pode surgir como conseqüência de imobilização prolongada. Achados de hipercalcemia sugerem presença de outros distúrbios, como o hiperparatiroidismo primário. Não está claro se há relação entre essas duas doenças, mas o hiperparatiroidismo tem sido relatado em 15 a $20 \%$ dos pacientes com DPO (11). O hiperparatiroidismo secundário pode ocorrer como resultado do aumento do turnover ósseo na doença de Paget. O uso de bisfosfonato também pode induzir ao hiperparatiroidismo, que pode ser evitado com a suplementação de cálcio e vitamina $\mathrm{D}$. No entanto, é improvável que o aumento da função das paratiróides seja um evento conseqüente à doença de Paget.

As complicações mais freqüentes incluem fraturas patológicas, deformidades ósseas, artrite degenerativa, perda da audição, compressão nervosa, hipercalcemia durante a imobilização, aumento do débito cardíaco nos casos de envolvimento ósseo severo e mais raramente de osteossarcoma.

\section{TRATAMENTO}

O tratamento tem como objetivo restaurar o metabolismo ósseo normal, alívio da dor óssea e prevenção das complicações futuras, em particular as deformidades ósseas, osteoartrites secundárias, fraturas e compressão das estruturas nervosas.

As indicações para o tratamento incluem o alívio dos sintomas causados pela doença metabolicamente ativa, preparo para cirurgia ortopédica para reduzir sangramento, hipercalcemia por imobilização e prevenção da progressão da doença.

A calcitonina do salmão foi a primeira droga efetiva a ser disponível para tratamento da doença de Paget. Atua diminuindo o turnover ósseo e no alívio da dor. Uma redução das lesões osteolíticas pode ser vista radiologicamente dentro de 6 meses (12). Porém, é menos efetiva do que os bisfosfonatos. É usada na dose inicial de 100 U SC ao dia durante 3 a 6 meses; após este período a dose deve ser reduzida (13). A duração da terapia depende da atividade da doença e resposta do paciente. A normalização da fosfatase alcalina é incomum e só ocorre em pacientes com pequeno aumento do turnover ósseo. A supressão da 
atividade da doença não persiste por longo tempo após a suspensão da droga, ocorrendo remissão cedo e resistência freqüente. Anticorpos se desenvolvem em cerca de 30 a $60 \%$ dos pacientes $(14,15)$. Efeitos colaterais ocorrem em cerca de $10 \%$ dos pacientes tratados e incluem náuseas, gosto metálico e rubor facial.

Os bisfosfonatos são análogos do pirosfosfato, cuja ponte de oxigênio é substituída por um carbonato ligado a várias cadeias laterais. Suas ligações características de fósforo-carbono-fósforo (P-C-P) os tornam resistentes à hidrólise das fosfatases, permitindo sua ligação com a matriz óssea calcificada. Possuem elevada afinidade de ligação com cátions bivalentes, principalmente cálcio. Esta propriedade parece ser responsável em parte pelo potente efeito farmacológico desta classe de medicações, que se ligam fortemente à hidroxiapatita óssea. Os bisfosfonatos ligam-se às superfícies ósseas, preferencialmente em áreas de elevado turnover ósseo. São potentes inibidores da reabsorção óssea osteoclástica, tendo demonstrado eficácia no tratamento de doenças ósseas metabólicas, tais como osteoporose, hipercalcemia da malignidade, metástases ósseas e no tratamento da doença de Paget, sendo considerados atualmente como o tratamento de primeira escolha. Quando usados por via oral são pobremente absorvidos, variando de 0,5 até 3\%, especialmente na presença de alimentos ou mesmo com pequenas quantidades de sais de cálcio. Por esta razão, devem ser administrados com um copo de água, permanecendo em jejum por pelo menos 30 minutos. A captação pelo esqueleto é cerca de $50 \%$ da dose absorvida, mas esta proporção pode variar de acordo com o turnover ósseo e é mais acentuada nos locais de reabsorção óssea ativa. Os bisfosfonatos diferem entre si pela substituição das cadeias laterais ativas do átomo de carbono na estrutura P-C-P, e são agrupados em duas classes com diferentes mecanismos de ação: aqueles que contêm nitrogênio na cadeia lateral, tais como o pamidronato, alendronato, risedronato e ácido zoledrônico, e os que não contêm um grupo de nitrogênio, como o etidronato. $\mathrm{O}$ mecanismo de ação dos que possuem nitrogênio na cadeia lateral é a inibição da remodelação óssea mediada pelos osteoclastos, por prevenir a prenilação de algumas proteínas formadas na via metabólica da síntese do colesterol (16). Essas proteínas regulam os processos que são importantes para a função dos osteoclastos, como a formação das bordas onduladas e a organização celular, levando a perda de função e sua morte por apoptose. Em contraste, aqueles bisfosfonatos que não contêm nitrogênio na cadeia lateral (etidronato, clodronato) prejudicam a síntese de ATP, resultando em apoptose dos osteoclastos.
O primeiro bisfosfonato usado na doença de Paget foi o etidronato, em 1971 (17). A dose preconizada é de $5 \mathrm{mg} / \mathrm{kg}$ ao dia (dose média 400 $\mathrm{mg} / \mathrm{dia})$ por 6 meses $(17,18)$. Em geral, pacientes com muita atividade da doença têm moderada melhora clínica e bioquímica e recidiva rápida após a interrupção da medicação, com tendência a tornarem-se resistentes após repetidos cursos da terapia. Estudos histológicos do osso mostraram osteomalácia em osso pagético e não pagético, após tratamento com 10 a 20 $\mathrm{mg}$ ao dia, mas não com dose de $5 \mathrm{mg}$ ao dia $(19,20)$.

O pamidronato é 10 a 100 vezes mais potente de que o etidronato e induz a redução da remodelação óssea em $60-70 \%(21,22)$. É mais utilizado por via parenteral na dose de $60 \mathrm{mg}$ em uma única infusão em casos de pouca atividade da doença (fosfatase alcalina 2 a 3 vezes acima do valor normal máximo). Doses maiores $(90-180 \mathrm{mg}$ ) podem ser usadas em intensidade moderada a severa, em infusões por 3 dias seguidos ou semanais (23). A dose máxima utilizada em um dia é $90 \mathrm{mg}$, diluída em soro glicosado ou fisiológico, durante 4-6 horas. Efeitos colaterais podem surgir, como hipocalcemia, febre, sintomas gripais e leucopenia transitória (24). Esses sintomas são também comuns a outros bisfosfonatos potentes, quando usados por via intravenosa.

O alendronato oral é mais efetivo no tratamento da doença de Paget de que o etidronato. Pode ser usado na dose de $20 \mathrm{mg}$ a $40 \mathrm{mg} /$ dia por 6 meses (25). Na dose de $40 \mathrm{mg} /$ dia por 6 meses leva a uma redução de $77 \%$ da fosfatase alcalina comparado com $44 \%$ de redução com etidronato (26). A normalização da fosfatase alcalina também é mais freqüente nos pacientes tratados com alendronato $(63,4 \%$ vs. $17 \%$ ) do que com etidronato.

O tiludronato é recomendado na dose de 400 $\mathrm{mg} /$ dia por 3 meses, normalizando a fosfatase alcalina em $35 \%$ dos pacientes (27). É mais efetivo de que o etidronato e não causa desmineralização óssea (28).

O clodronato tem maior potência de que o etidronato e não leva a defeitos de mineralização. Deve ser administrado por via intravenosa na dose de 300 $\mathrm{mg}$ ao dia por 5 dias (29), porém, em geral, é menos efetivo de que o pamidronato.

$\mathrm{O}$ risedronato na dose de $30 \mathrm{mg}$ ao dia por 2 meses, comparado com etidronato na dose de $400 \mathrm{mg}$ ao dia durante 6 meses, leva à normalização da fosfatase alcalina em 73\%, comparado com $15 \%$ de redução com etidronato. Após 16 meses da suspensão das medicações, $53 \%$ dos pacientes com risedronato permanecem em remissão, em comparação com 14\% daqueles com etidronato (30). Em pacientes com 
resistência a calcitonina e pamidronato, associada a doença óssea severa, o risedronato foi capaz de reduzir significativamente os níveis de fosfatase alcalina (31).

O ibandronato é outro bisfosfonato que também tem sido usado com segurança e eficácia na doença de Paget, na dose de $2 \mathrm{mg}$ por via intravenosa (32).

O ácido zoledrônico (zoledronato) é uma nova geração de bisfosfonato (terceira geração) e parece ser o bisfosfonato mais potente. É 10.000 vezes mais potente que o etidronato e 100 vezes mais que o pamidronato (33). Em contraste com os demais bisfosfonatos à base de nitrogênio, o ácido zoledrônico possui 2 átomos de nitrogênio em um anel imidazol heterocíclico. Em culturas de osteoclastos humanos e de coelhos, o ácido zoledrônico $(100 \mathrm{nM})$ induz à apoptose e aumenta a atividade da caspase-3-similar (34). Atualmente, há forte evidência de que os bisfosfonatos à base de nitrogênio exercem seus efeitos celulares por meio da inibição específica de uma enzima na via do mevalonato, a farnesil difosfato sintase (35). A inibição da via do mevalonato em osteoclastos intactos tratados com ácido zoledrônico também foi demonstrada e, em culturas de osteoclastos maduros de coelhos in vitro, inibiu a prenilação das proteínas de modo dependente da concentração, com inibição acentuada já aparente na concentração de $10 \mathrm{nM}$. O ácido zoledrônico pode ser infundido por via intravenosa por um tempo mais curto (15-20 minutos) e volume (soro fisiológico ou glicosado) mínimo de 100 ml. Em relação aos efeitos adversos, o risco de hipofosfatemia, hipocalemia e hipocalcemia semelhante aos outros bisfosfonatos é baixo, como também febre, calafrios, mialgia e artralgia. Em relação à osteonecrose de mandíbula, que vem sendo relatada com o uso de bisfosfonato, não existe referência na literatura de que esta complicação ocorra com o ácido zoledrônico na dose usada no tratamento da doença de Paget. Tem-se observado apenas em doses altas usadas nos pacientes com doença malígna $(36,37)$. Não é aconselhável seu uso em pacientes com comprometimento renal grave (clearance de creatinina $<30$ $\mathrm{ml} / \mathrm{min}$ ). Parece ser mais efetivo do que o pamidronato na hipercalcemia da malignidade (38), e temse demonstrado um ganho de massa óssea de $5 \%$ em mulheres na pós-menopausa, com densidade mineral óssea baixa, após um período de um ano, seguido de uma única infusão de $4 \mathrm{mg}$ (39). Pacientes com resistência a outros bisfosfonatos no tratamento de doença de Paget em atividade podem responder ao ácido zoledrônico, como evidenciado no estudo de Chung (40), em que um paciente com doença poliostótica severa persistia com doença em atividade seguindo-se ao uso de calcitonina, etidronato, tiludronato e vários cursos de infusão de pamidronato, e após uma única infusão venosa de $4 \mathrm{mg}$ de ácido zoledrônico houve normalização dos níveis de fosfatase alcalina 6 meses depois, caindo de $569 \mathrm{U} / 1$ para $85 \mathrm{U} / 1$ (normal 30-130). O primeiro estudo em humanos (fase 1) com o ácido zoledrônico, comparando várias doses, mostrou que a atividade anti-absortiva foi observada dentro de poucos dias após uma única infusão (41). O ácido zoledrônico é altamente eficaz em reduzir os marcadores bioquímicos da remodelação óssea. Esta ação foi mostrada num estudo (42) em que se avaliou o efeito do ácido zoledrônico na dose de $4 \mathrm{mg}$ em uma única infusão nos marcadores de remodelação óssea (C-telopeptídeo e fosfatase alcalina) em 10 pacientes com doença de Paget ativa. Foram 3 homens e $7 \mathrm{mu}-$ lheres ( 3 com doença monostótica e 7 com a poliostótica) com idades entre 50 e 80 anos. A média do desvio-padrão da fosfatase alcalina foi de 416,4 \pm intensidade $336 \mathrm{U} / \mathrm{L}(3,3 \pm 3$ vezes o limite superior do normal) e do C-telopeptídeo (CTX) 1290,4 \pm $580,6 \mathrm{pg} / \mathrm{ml}(2,8 \pm 1,3$ vezes o limite superior do normal). $\mathrm{O}$ ácido zoledrônico foi a primeira terapia em 2 pacientes, e 8 pacientes tinham sido tratados anteriormente com alendronato ou risedronato. Os pacientes foram avaliados, em média, 6 meses após a infusão do ácido zoledrônico. A média de redução da fosfatase alcalina foi de $72,6 \% \pm 11,9 \%$, e a do Ctelopeptídeo foi de $70,6 \% \pm 19,9 \%$. O percentual de redução nos valores de fosfatase após o tratamento não foi diferente do observado nos valores do CTX, seguindo-se à infusão do ácido zoledrônico. A normalização da fosfatase alcalina foi alcançada em 9 pacientes e a do C-telopeptídeo em 7. Em um paciente com doença poliostótica, em que os marcadores não alcançaram os níveis normais, houve uma queda da fosfatase alcalina de $70 \%$ e do C-telopeptídeo de $63 \%$.

$\mathrm{O}$ acido zoledrônico pode levar a uma remissão mais rápida e prolongada no tratamento da doença de Paget do que o risedronato (43). Quando avaliado por 6 meses após uma única infusão de $5 \mathrm{mg}$ administrada durante 15 minutos, tendo como eficácia da resposta a normalização da fosfatase alcalina ou atingir uma queda de pelo menos $75 \%$, levou a uma redução de $96 \%$ da fosfatase alcalina quando comparada com $74,3 \%$ de redução com risedronato na dose de $30 \mathrm{mg}$ ao dia, durante 3 meses. A normalização da fosfatase alcalina foi mais freqüentemente atingida nos pacientes tratados com o ácido zoledrônico (88,6\% vs. $57,9 \%)$ do que com risedronato.

A característica química do ácido zoledrônico prolonga sua meia-vida no osso e permite exercer seu 
Tabela 1. Principais bisfosfonatos usados no tratamento da doença de Paget.

\begin{tabular}{lccc}
\hline DROGA & NOME COMERCIAL & DOSE & DURAÇÃO \\
\hline Etidronato & Didronele $^{\circledR}$ & $400 \mathrm{mg} / \mathrm{dia}-\mathrm{VO}$ & Seis meses \\
Pamidronato & Aredia $^{\circledR}$ & $60 \mathrm{a} 90 \mathrm{mg}-\mathrm{IV}$ & $1-4$ infusões semanais \\
Alendronato & Fosamax $^{\circledR}$ & $20 \mathrm{a} 40 \mathrm{mg} / \mathrm{dia}-\mathrm{VO}$ & Seis meses \\
Tiludronato & Skelid $^{\circledR}$ & $400 \mathrm{mg} / \mathrm{dia}-\mathrm{VO}$ & Três meses \\
Clodronato & Ostac $^{\circledR}$ & $300 \mathrm{mg} / \mathrm{dia}-\mathrm{IV}$ & Cinco dias \\
Risedronato & Actonel $^{\circledR}$ & $30 \mathrm{mg} / \mathrm{dia}-\mathrm{VO}$ & Dois meses \\
lbandronato & - & $2 \mathrm{mg}-\mathrm{IV}$ & Infusão única \\
Zoledronato & Zometa $^{\circledR} /$ Aclasta $^{\circledR}$ & $4 \mathrm{mg} \mathrm{a} 5 \mathrm{mg}-\mathrm{IV}$ & Infusão única \\
\hline
\end{tabular}

efeito no esqueleto durante meses e talvez anos após sua administração. Todos os pacientes tratados com bisfosfonatos devem receber suplementação de cálcio e vitamina D. A tabela 1 apresenta os principais bisfosfonatos disponíveis no tratamento da doença de Paget.

\section{SEGUIMENTO}

No seguimento dos pacientes com doença de Paget, considera-se remissão quando são atingidos níveis normais dos marcadores bioquímicos, como a fosfatase alcalina, e remissão parcial quando há queda de mais de $75 \%, 3$ a 6 meses após o início do tratamento. A fosfatase alcalina deve ser dosada a cada 3-6 meses após o curso da terapia, e um novo tratamento deverá ser instituído quando a fosfatase alcalina voltar a se elevar no caso de normalização com o tratamento, ou quando houver elevação de mais de $25 \%$ em relação ao nível pós-tratamento. Os marcadores de reabsorção óssea, como o C-telopeptídeo, apresentam alta sensibilidade, principalmente nos indivíduos com fosfatase alcalina normal (44).

Os procedimentos cirúrgicos estão indicados em certas situações, tais como prótese de quadril, em caso de osteoartrite severa, osteotomia tibial para correção de uma tíbia deformada, craniotomia occipital para descompressão da fossa posterior em pacientes com platibasia e para descompressão de nervos.

Os pacientes que vão ser submetidos a cirurgia eletiva devem receber uma infusão venosa de 60-90 $\mathrm{mg}$ de pamidronato em 4-6 horas, ou $5 \mathrm{mg}$ de ácido zoledrônico por 15-20 minutos, para reduzir a hipervascularidade e, deste modo, diminuir o sangramento durante a cirurgia. Isto pode ser feito uma semana antes do procedimento cirúrgico.

Em relação ao controle da dor, quando diretamente atribuída à doença de Paget, é geralmente aliviada pelo tratamento anti-reabsortivo (bisfosfonato ou calcitonina). Em outras ocasiões, a dor resulta da deformidade óssea ou artrite. Nestes casos, o uso de acetominofen, antiinflamatórios não-esteróides ou inibidores da cox- 2 podem ser úteis no alívio da dor.

\section{CONCLUSÃO}

O desenvolvimento de inibidores específicos da reabsorção óssea mediada pelos osteoclastos, particularmente os bisfosfonatos de última geração tais como o alendronato, risedronato e o ácido zoledrônico, permitiu maiores chances de sucesso no tratamento da doença de Paget nos últimos anos, mesmo naqueles casos de doença óssea mais severa. Embora os efeitos da supressão da doença a longo prazo sejam desconhecidos, a restauração do processo de remodelação óssea ao normal permite acreditar que a redução das complicações a longo prazo seja possível. Atualmente, o ácido zoledrônico parece ser a melhor opção de tratamento devido à sua maior potência e remissão prolongada, em uma única infusão de curto tempo (15-20 $\mathrm{min})$.

\section{REFERÊNCIAS}

1. Paget J. On a form of chronic inflammation of bone (osteitis deformans). Medico-Surgical Transactions of London 1887; 60:37-63.

2. Bandeira F, Griz L, Caldas G, Macedo G, Campos R, Marinho $C$, et al. Paget's disease of bone - Characteristics of 49 patients from a single institution in Recife, $\mathrm{PE}$, Brazil. J Bone Miner Res 1999; 14(suppl. 1):S539.

3. Siris ES. Epidemiologic aspects of Paget's disease of bone: Family history and relationship to other medical conditions. Semin Arthritis Rheum 1994;23:222.

4. Roodman GD, Windle J. Paget disease of bone. J Clin Invest 2005; 1 15:200-8.

5. Reddy SV, Singer FR, Mallette L, Roodman GD. Detection of measles virus nucleocapsid transcripts in circulating blood cells from patients with Paget's disease. J Bone Miner Res 1996; 11:602-7.

6. Friedrichs WE, Sakamuri VR, Bruder JM, Cundy T, Cornish $J$, Singer $F$, et al. Sequence analysis of measles virus nucleocapsid transcripts in patients with Paget's disease. J Bone Miner Res 2002; 17:145-51.

7. Siris ES, Chines AA, Altman RD, Brown JP, Johnston CC Jr, Lang $R$, et al. Risedronate in the treatment of Paget's disease of bone: An open label, multicenter study. J Bone Miner Res 1998; 13(6): 1032-8.

8. Hosking D, Meunier PJ, Ringe JD, Reginter JY, Gennari C. Fortnightly review: Paget's disease of bone: Diagnosis and management. BMJ 1996;312:491-4. 
9. Delmas PD, Meunier PJ. The management of Paget's disease of bone. N Engl J Med 1977;336:558-66.

10. Moore TE, Kathol MH, el-Khoury GY, Walker CW, Gendall PW, Whitten CG. Unusual radiologic features in Paget's disease of bone. Skeletal Radiol 1994;23(4):257-60.

11. Posen S, Clifton-Bligh P, Wilkinson M. Paget's disease of bone and hyperparathyroidism: Coincidence or casual relationship? Calcif Tissue Res 1978;26(2):107-9.

12. Woodhouse NJY, Chalmers AH, Wells IP, Dewbury KC, Mohamedally SM. Paget's disease: Radiological changes occurring in untreated patients and those on therapy with salmon calcitonin during two years' observation. Br J Radiol 1977;50:699-705.

13. Singer FR. Clinical efficacy of salmon calcitonin in Paget's disease of bone. Calcif Tissue Int 1991:49(suppl. 12):57.

14. Singer FR, Aldred JP, Neer RM, Krane SM, Potts JT Jr, Bloch KJ. An evaluation of antibodies and clinical resistance to salmon calcitonin. J Clin Invest 1972:51:2331-8.

15. Dietrich FM, Fisher JA, Bijvoet OLM. Formation of antibodies to synthetic human calcitonin during treatment of Paget's disease. Acta Endocrinol 1979:92:468-76.

16. Russell RG, Rogers MJ, Frith JC, Luckman SP, Coxon FP, Benford $\mathrm{HL}$, et al. The pharmacology of bisphosphonates and new insights into their mechanism of action. $J$ Bone Miner Res 1999; 14(suppl. 2):53-65.

17. Smith R, Russell RG, Bishop M. Bisphosphonates and Paget's disease of bone. Lancet 1971;1:945-7.

18. Alman RD, Johnston CC, Khairi MRA, Wellman H, Scrafini NA, Sankey RR. Influence of disodium etidronate on clinical and laboratory manifestations of Paget's disease of bone. N Engl J Med 1973;289:1379-84.

19. Meunier PJ, Revault A. Treatment of Paget's disease with etidronate disodium. In: Singuer FR, Wallach S (eds). Paget's disease of bone: Clinical assessment, present and future therapy. New York: Elsevier, 1991. pp. 86-99.

20. Alexandre CM, Collins B. Disodium etidronate in Paget's disease: 11-year study of 93 patients. Arthritis Rheum 1983;26(suppl.):S9.

21. Frijlink WB, Bijvoet $O L$, te Velde J, Heynen $G$. Treatment of Paget's disease with (3-amino-1-hydroxypropylidene)-1, 1-bisphosphonate (A.P.D.). Lancet 1979; 1(8120):799-803

22. Cantrill JA, Anderson DC. Treatment of Paget's disease of bone. Clin Endocrinol 1990;32:507-18.

23. Lufkin EG, Argueta R, Whitaker MD, Cameron AL, Wong $\mathrm{VH}$, Egan KS, et al. Pamidronate: an unrecognized problem in gastrointestinal tolerability. Osteoporos Int $1994: 4: 320-2$

24. Thiebaud D, Jaeger $P$, Gobelet $C$. A single infusion of the bisphosphonate (AMP) as treatment of Paget's disease of bone. Am J Med 1988:85:207-12.

25. Reid IR, Siris E. Alendronate in the treatment of Paget's disease of bone. Int Clin Pract 1999;101:62-6.

26. Siris E, Weinstein RS, Altman R, Conte JM, Favus M, Lombardi $A$, et al. Comparative study of alendronate and etidronate for the treatment of Paget's disease of bone. J Clin Endocrinol Metab 1996:81:961-7.
27. McClung MR, Tou CK, Goldstein NH, Picot C. Tiludronate therapy for Paget's disease of bone. Bone 1995; 17(suppl.):493S-6.

28. Roux C, Gennari C, Farrerons J, Devogelaer JP, Mulder $\mathrm{H}$, Kruse HP, et al. Comparative prospective, doubleblind, multicenter study of the efficacy of tiludronate and etidronate in the treatment of Paget's disease of bone. Arthritis Rheum 1995;38(6):851-8.

29. Yates AJ, Percival RC, Gray RE, Atkins RM, Urwin GH, Hamdy NA, et al. Intravenous clodronate in the treatment of Paget's disease of bone. Lancet 1985; 1:1474-7.

30. Miller PD, Brown JP, Siris ES, Hoseyni MS, Axelrod DW, Bekker PJ. A randomized, double-blind comparison of risedronate and etidronate in the treatment of Paget's disease of bone. Paget Risedronate / Etidronate Study Group. Am J Med 1999; 106(5):513-20.

31. Singuer FR, Clemens TL, Eusebio RA, Bekker PJ. Risedronate, a highly effective oral agent in the treatment of patients with severe Paget's disease. J Clin Endocrinol Metab1998;83(6):1906-10.

32. Grauer A, Heichel S, Knaus J, Dosch E, Ziegler R. Ibandronate treatment in Paget's disease of bone. Bone 1999;24(suppl.5):87S-9.

33. Fleisch $\mathrm{H}$. Bisphosphonates in bone disease from the laboratory to the patient, $2^{\text {nd }}$ ed. London: Partenon, 1995.

34. Coxon FP, Helfrich MP, van'† Hof R, Sebit S, Ralston SH, Hamilton $\mathrm{A}$, et al. Protein geranyllation is required for osteoclastic formation, function survival: Inhibition by bisphosphonates and GGTI-298. J Bone Miner Res 2000; 15:1467-76.

35. Dunford JE, Thompson K, Coxon FG, Luckman SP, Hahn FM, Poulter CD, et al. Structure-activity relationships for inhibition of farnesyl diphosphate synthase in vitro and inhibition of bone resorption vivo by nitrogen-containing bisphosphonates. J Pharm Exp Ther 2001:296:235-42.

36. Ferrugia MC, et al. Osteonecrosis of mandible/maxilla and use of new bisphosphonates. Laryngoscope 2006; 1 15-20.

37. Hoff $\mathrm{AO}$, et al. Osteonecrosis of the jaw in patients receiving intravenous bisphosphonates therapy. J Bone Miner Res 2005;20(suppl. 1):S53.

38. Major PP, Coleman RE. Zoledronic acid in the treatment of hypercalcemia of malignancy: Result of the international clinical development program. Semin Oncol 2001;28(suppl. 6):17-24.

39. Reid IR, Brown JP, Burckhardt P, Horowitz Z, Richardson P, Trechsel $U$, et al. Intravenous zoledronic acid in post menopausal women with low bone mineral density. $\mathbf{N}$ Engl J Med 2002;346(9):653-61.

40. Chung $G$, Keen RN. Zoledronate treatment in active Paget's disease. Ann Rheum Dis 2003;62:275-6.

41. Arden M, Siris ES, Lyles KW, Knieriem A, Newton RA, Schaffer $V$, et al. Antiresorptive effect of a single infusion of microgram quantities of Zoledronate in Paget's disease of bone. Calcif Tissue Int 1997:60:415-8.

42. Bandeira F, Griz L, Caldas G, Saraiva W, Carvalho W, Rosado VA. Serum C-telopeptide and alkaline phosphatase changes following a single intravenous infusion of zoledronic acid in patients with Paget's disease. J Bone Miner Res 2003; 18(suppl):S389, 
43. Reid IR, Miller P, Lyles K, Fraser W, Brown JP, Saidi Y, et al. Comparison of a single infusion of zoledronic acid with risedronate for Paget's disease. N Engl J Med 2005;353(9):898-908.

44. Bandeira F, Griz L, Caldas G, Bandeira C. Paget's disease of bone with normal serum alkaline phosphatase activity-effects of bisphosphonates on clinical symptoms and bone markers. J Bone Miner Res 2001;16 (suppl):S301.

\section{Endereço para correspondência:}

Luiz Griz

Estrada das Ubaias 332, apto. 302

52061-080 Recife, PE

E-mail: luizgriz@globo.com 